\title{
Estudo dos impactos de vizinhança das indústrias de médio e grande porte na zona sul de Teresina/PI
}

O Estudo de Impacto de Vizinhança é um documento de análise urbanística e ambiental de âmbito municipal e se destina a empreendimentos dos mais diverso segmentos que impactos no meio ambiente. O objetivo do presente trabalho é analisar os impactos de vizinhança no entorno das indústrias de médio e grande porte na zona Sul de Teresina no que se refere aos aspectos legais. Os métodos utilizados foram: pesquisa bibliográfica e eletrônica em fontes digitais de informação como em anais de ventos, revistas científicas, etc.; levantamento dos dados das indústrias; verificação da situação cadastral das empresas; espacialização das indústrias por meio de geotecnologias; pesquisa documental das leis municipais; atividade de campo e registro fotográfico. Conforme resultados, constatou-se diversos impactos no meio físico, urbanístico, infraestrutura e qualidade de vida, a citar, ocupação irregular do solo por moradores em área de proteção ambiental, resíduos sólidos e pontos de queimada, geração de tráfego, ponto de água servida acumulada e esgoto irregular. Conclui-se que, aplicabilidade das ferramentas de geoprocessamento é de fundamental importância para a espacialização por meio de mapas temáticos de uso e ocupação do solo, visto que, essa visualização espacial possibilita um melhor entendimento da abrangência dos impactos na vizinhança e de áreas de ocupação irregular, servindo como uma ferramenta suporte para a tomada de decisões. É necessária atenção por parte do Poder Municipal na adoção de medidas mitigadoras e compensatórias a cerca dos impactos de vizinhança que interferem diretamente na qualidade de vida dos moradores.

Palavras-chave: Impactos; Atividade Industrial; Zona Urbana; Teresina.

\section{Study of neighborhood impacts of medium and biggy industries in the south of Teresina/PI}

\begin{abstract}
The Neighborhood Impact Study is an urban and environmental analysis document of municipal scope and is intended for projects of the most diverse segment that impacts on the environment. The objective of the present work is to analyze the impacts of neighborhood in the surroundings of the medium and large industries in the South zone of Teresina with regard to the legal aspects. The methods used were: bibliographical and electronic research in digital sources of information such as wind annals, scientific journals, etc.; survey of industry data; verification of the cadastral situation of the companies; spatialization of industries through geotechnology; documentary research of municipal laws; field activity and photographic record. According to the results, there were several impacts on the physical environment, urban planning, infrastructure and quality of life, to mention, irregular occupation of the soil by residents in environmental protection area, solid waste and burning points, generation of traffic, water point served accumulated and uneven sewage. It is concluded that the applicability of the geoprocessing tools is of fundamental importance for the spatialisation through thematic maps of land use and occupation, since this spatial visualization allows a better understanding of the extent of the impacts in the neighborhood and occupation areas irregular, serving as a support tool for decision-making. Municipal Government attention is needed in the adoption of mitigating and compensatory measures regarding neighborhood impacts that directly interfere with the residents' quality of life.
\end{abstract}

Keywords: Impacts; Industrial Activity; Urban area; Teresina.

Topic: Desenvolvimento, Sustentabilidade e Meio Ambiente

Reviewed anonymously in the process of blind peer.

Núbia Araújo Sena (iD

Instituto Federal do Piauí, Brasil

http://lattes.cnpq.br/7287388071342868

http://orcid.org/0000-0001-7998-6746

nubia.sena@live.com

Bruna de Freitas Iwata (iD)

Instituto Federal do Piauí, Brasil

http://lattes.cnpq.br/3036032785449787

http://orcid.org/0000-0002-6465-9731

iwata@ifpi.edu.br

Karoline de Sousa Almeida (10)

Instituto Federal do Piauí, Brasil

http://lattes.cnpq.br/4868199952833171

http://orcid.org/0000-0003-2436-4856

almeidakarol300@gmail.com

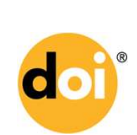

DOI: 10.6008/CBPC2179-6858.2019.003.0021
Received: $12 / 04 / 2019$

Approved: 27/05/2019

\section{Referencing this:}

SENA, N. A.; IWATA, B. F.; ALMEIDA, K. S.. Estudo dos impactos de vizinhança das indústrias de médio e grande porte na zona sul de Teresina/PI. Revista Ibero Americana de Ciências Ambientais, v.10, n.3, p.238-251, 2019. DOI: http://doi.org/10.6008/CBPC21796858.2019.003.0021 


\section{INTRODUÇÃO}

O Estudo de Impacto de Vizinhança é um dos documentos de estudo de impacto ambiental de âmbito local. Existem também outros documentos de estudo de impacto ambiental, como o Plano de Controle Ambiental - PCA, Relatório Ambiental Simplificado - RAS, Memorial Descritivo - MED e Estudo de Impacto Ambiental - EIA e consequente relatório (RIMA), este caracteriza-se em um estudo mais completo.

Conforme é colocado no Estatuto da Cidade (BRASIL, 2001), o EIV deverá contemplar os efeitos positivos e negativos do empreendimento ou atividade quanto à qualidade de vida da população residente na área e suas proximidades, incluindo a análise, no mínimo, das seguintes questões: I - adensamento populacional; II - equipamentos urbanos e comunitários; III - uso e ocupação do solo; IV - valorização imobiliária; V - geração de tráfego e demanda por transporte público; VI - ventilação e iluminação; VII paisagem urbana e patrimônio natural e cultural (BRASIL, 2001).

Dessa forma, o Estatuto da Cidade - Lei no 10.257 de 10 de julho de 2001 - estabelece normas de ordem pública e interesse social que regulam o uso da propriedade urbana em prol do bem coletivo, da segurança e do bem-estar dos cidadãos, bem como do equilíbrio ambiental através do EIV e consequente RIV. Tal Lei é utilizada enquanto instrumento mediador entre interesse privado e a garantia da qualidade de vida da população urbana em seu entorno (BRASIL, 2001).

De acordo com a Lei no 3.565 (TERESINA, 2006), são considerados empreendimentos ou atividades econômicas geradoras de impacto de vizinhança aqueles que, quando implantados: I - sobrecarregam a infraestrutura urbana, interferindo direta ou indiretamente no sistema viário, sistema de drenagem, saneamento básico, eletricidade e telecomunicações; II - tenham uma repercussão ambiental significativa, provocando alterações nos padrões funcionais e urbanísticos da vizinhança ou na paisagem urbana e patrimônio natural circundante; III - estabeleçam alteração ou modificação substancial na qualidade de vida da população residente na área ou em suas proximidades, afetando sua saúde, segurança ou bem-estar; IV alterem as propriedades químicas, físicas ou biológicas do meio ambiente; $V$ - prejudiquem o patrimônio cultural do município.

Analisando a Lei Municipal, observa-se que está com consonância com a Lei Federal a respeito dos impactos mínimos a serem analisados no EIV, conforme está impõe a responsabilidade ao Poder Público municipal. Nos últimos anos, a temática ambiental tem sido palco de debates no que diz respeito à necessidade de mudanças de percepção em diversos setores da sociedade, inclusive no setor industrial. crescimento e consequente desenvolvimento urbano das cidades através das atividades econômicas impactam no meio ambiente, interferindo na qualidade deste e refletindo na população que nele habita.

Faz-se necessário analisar os impactos nas áreas industriais no meio urbano por meios das diretrizes legais no âmbito ambiental, tendo em vista que, as atividades econômicas propiciam interações socioambientais diversificadas e a manutenção da qualidade ambiental é um aspecto importante, uma vez que, reflete diretamente na qualidade de vida.

A zona Sul da cidade de Teresina é a zona que mais possui indústrias dos mais diversos segmentos. 
Vale destacar que a referida zona possui bairros e áreas voltados especificamente para a atividade industrial, a citar o bairro Distrito Industrial e Polo Empresarial Sul, área localizada no bairro Pedra Miúda. As indústrias de grande e médio porte produzem impactos significativos em seu entorno que inferem diretamente na qualidade de vida dos seres vivos.

O presente trabalho tem como objetivo geral analisar os impactos de vizinhança no entorno das indústrias de médio e grande porte na zona Sul de Teresina no que se refere aos aspectos legais. Dentre os objetivos específicos tem-se: I - Levantar os dados das indústrias de médio e grande porte na zona Sul; II Averiguar as características ambientais das áreas das indústrias; III - Verificar os impactos de vizinhança das áreas do entorno das indústrias.

\section{MATERIAIS E MÉTODOS}

O estudo foi realizado na zona urbana da cidade de Teresina/PI (Figura 1), no bairro Distrito Industrial e área do Polo Empresarial Sul, no bairro Pedra Miúda. Primeiramente, foi realizado um levantamento dos dados das indústrias na zona Sul de Teresina por meio de análise documental do cadastro das indústrias da Federação das Indústrias do Estado do Piauí - FIEPI disponível online para consulta.

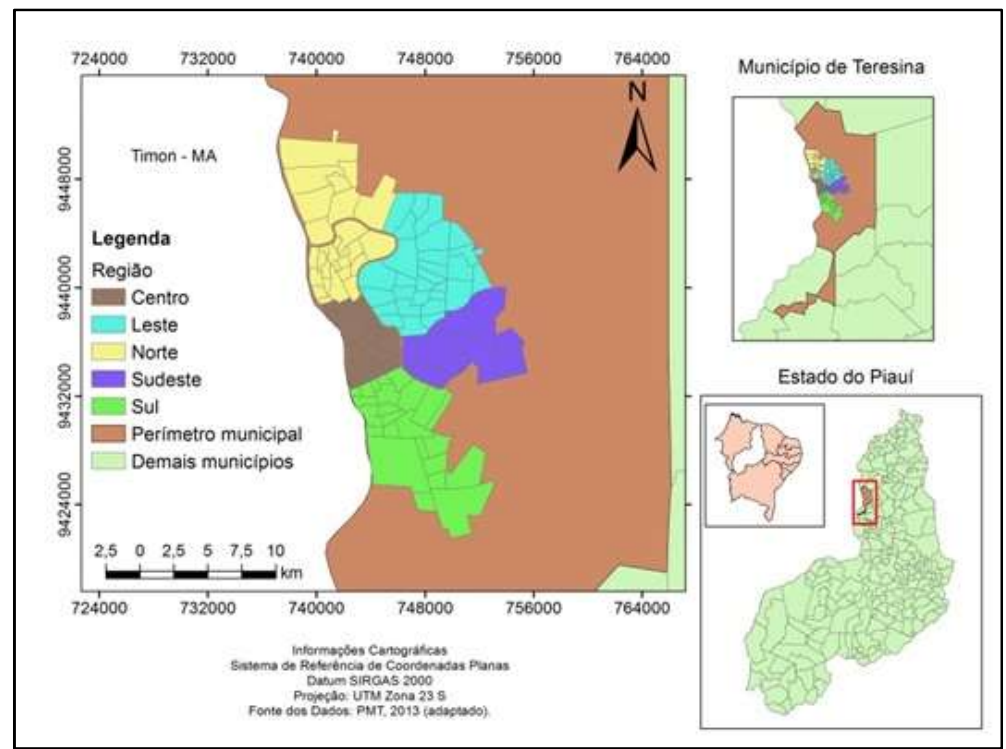

Figura 1: Localização da cidade de Teresina/PI.

Feito o levantamento do cadastro das indústrias da zona urbana de Teresina, foi realizado a consulta e emitido o comprovante de inscrição e de situação cadastral no site da Receita Federal para verificar o porte de cada empresa e se está se encontra ativa. De acordo com a explicação no site da Receita Federal, somente as naturezas jurídicas 206-2 (Sociedade Empresária Limitada), 207-0 (Sociedade Empresária em Nome Coletivo), 208-9 (Sociedade Empresária em Comandita Simples), 213-5 (Empresário Individual), 223-2 (Sociedade Simples Pura), 224-0 (Sociedade Simples Limitada), 225-9 (Sociedade Simples em Nome Coletivo), 226-7 (Sociedade Simples em Comandita Simples), 230-5 (Empresa Individual de Responsabilidade Limitada - Eireli, cuja natureza seja empresária) e 231-3 (Empresa Individual de Responsabilidade Limitada - Eireli, cuja natureza seja não empresária) exigem o enquadramento de porte da empresa. Para estas naturezas jurídicas, 
o porte pode ser 'ME' ou 'EPP'. Para o restante das naturezas jurídicas, o porte deve ser 'Demais' (IBGE, 2014). Dessa forma, entende-se como porte 'Demais' as empresas que antes eram classificadas como médio e grande porte.

Em seguida, obtiveram-se as coordenadas planas de cada empresa, utilizando o nome e o endereço no software Google Earth Pro, e com isso, foi realizada a espacialização das indústrias em um mapa por meio um Sistema de Informação Geográfica - SIG. Após esse procedimento, foram escolhidas para áreas de estudo o bairro Distrito Industrial, e a área do Polo Empresarial Sul, no bairro Pedra Miúda. Como a lei municipal n³.565 de Estudo Prévio de Impacto de Vizinhança (TERESINA, 2006) não impõe uma área de abrangência mínima de vizinhança, utilizou-se como perímetro de área a ser analisada neste trabalho, um raio de 300 metros das indústrias instaladas, conforme se vê na Figura 2.

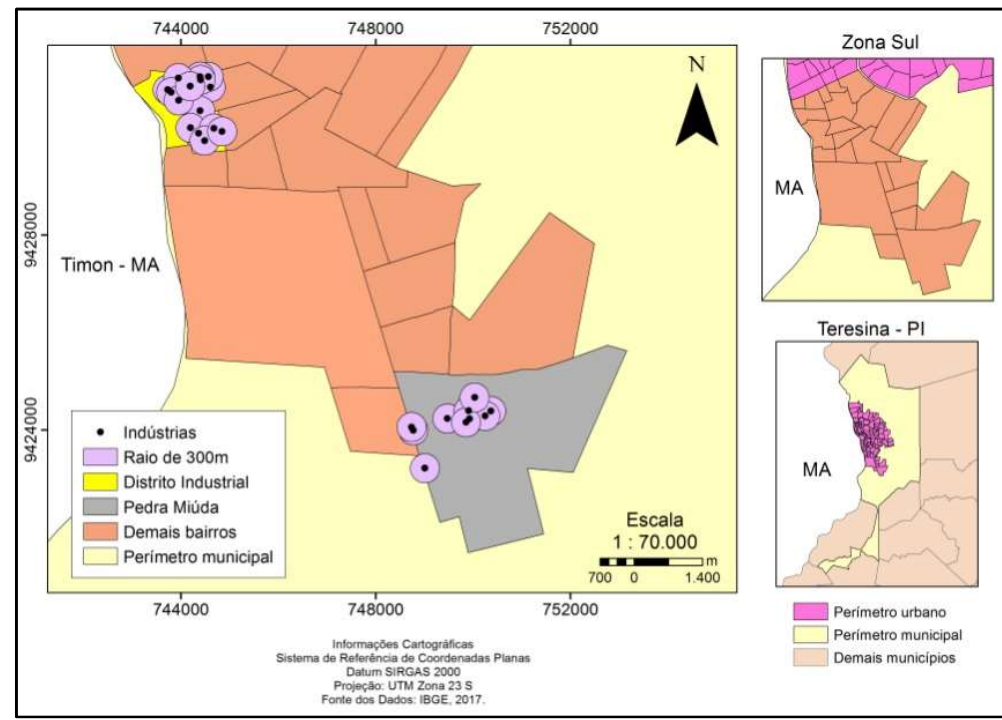

Figura 2: Raio de 300 metros das indústrias nas áreas de estudo.

\begin{tabular}{|c|c|c|c|c|c|}
\hline & & $\begin{array}{c}\text { Nartreza } \\
\text { (PosiơvoNegativo) }\end{array}$ & $\begin{array}{c}\text { Ordem } \\
\text { (Direas Indireta) }\end{array}$ & $\begin{array}{c}\text { Magnitade } \\
\text { (Alro:Medio-Baixo) }\end{array}$ & $\begin{array}{c}\text { Duraçá } \\
\text { (Permantente Temporásio) }\end{array}$ \\
\hline \multirow[t]{7}{*}{ Meio fisico } & solo e rochs & & & & \\
\hline & Relevo & & & & \\
\hline & Pais2zera Natural & & & & \\
\hline & Vezectastio & & & & \\
\hline & Oeupaço cusa dos do & & & & \\
\hline & Agua de Superficie & & & & \\
\hline & Aguz Subterrinez & & & & \\
\hline \multirow[t]{6}{*}{$\begin{array}{c}\text { Aspectos } \\
\text { Urbanisticos }\end{array}$} & $\begin{array}{l}\text { Adensamento } \\
\text { Populacional }\end{array}$ & & & & \\
\hline & Adensamento Urbino & & & & \\
\hline & Valonizaça lmobilinia & & & & \\
\hline & 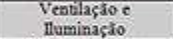 & & & & \\
\hline & Paiszagem Urbans & & & & \\
\hline & Património cultural & & & & \\
\hline \multirow[t]{8}{*}{ Infiracstrubura } & Gerajalo de trifego & & & & \\
\hline & Demindapor trassporte & & & & \\
\hline & Rede de agua & & & & \\
\hline & Rede de Es:50to & & & & \\
\hline & $\begin{array}{l}\text { Rede de Drenxgem } \\
\text { Piavial }\end{array}$ & & & & \\
\hline & Rede Elerica & & & & \\
\hline & Estacionameato & & & & \\
\hline & $\begin{array}{l}\text { Atteraçio no Sistema } \\
\text { Vistio }\end{array}$ & & & & \\
\hline \multirow[t]{3}{*}{$\begin{array}{l}\text { Qualidade de } \\
\text { Vida }\end{array}$} & Ruidos & & & & \\
\hline & Residuos Sollidos & & & & \\
\hline & Geragrao de emprego & & & & \\
\hline
\end{tabular}

Figura 3: Matriz para análise dos impactos de vizinhança.

Para a avaliação dos impactos de vizinhança, utilizou-se a matriz de impactos do trabalho de Molina Junior et al. (2012), onde aponta os impactos no meio físico, nos aspectos urbanísticos, na infraestrutura e na qualidade de vida, que são os tipos de impactos descritos tanto na lei federal quanto na lei municipal 
sobre os impactos de vizinhança, conforme mostra a Figura 3.

Para entender tal classificação dos impactos descrita na figura anterior, utilizou-se como referência a classificação da Deliberação da Comissão Estadual de Controle Ambiental - CECA do Rio de Janeiro no1078 (1987, citado por KAPUSTA et al., 2009), que classifica os impactos ambientais em treze tipos, conforme mostra no Quadro 1.

Quadro 1: Classificação dos impactos ambientais.

\begin{tabular}{|l|l|}
\hline Impacto & Descrição \\
\hline Positivo ou benéfico & Resulta na melhoria da qualidade de um fator ou parâmetro ambiental. \\
\hline Negativo ou adverso & Resulta em um dano à qualidade de um fator ou parâmetro ambiental. \\
\hline Direto & Resultado da simples ação causa e efeito \\
\hline Indireto & Resultante de uma reação secundária, ou quando é parte de uma cadeia de reações. \\
\hline Local & Afeta o próprio sítio e suas imediações. \\
\hline Regional & Se fizer sentir além das imediações do sítio. \\
\hline Estratégico & Tem relevância no âmbito regional e nacional. \\
\hline Imediato & O efeito surge no instante em que se dá a ação \\
\hline Médio e longo prazo & Os efeitos da ação são verificados posteriormente. \\
\hline Temporário & Efeito da ação tem duração determinada. \\
\hline Permanente & Quando o impacto não pode ser revertido \\
\hline Cíclico & Os efeitos se manifestam em intervalos de tempo determinados. \\
\hline Reversível & Quando cessada a ação, o ambiente volta à sua forma original. \\
\hline
\end{tabular}

Verificando o Quadro 1, nota-se a variedade dos impactos, segundo o seu efeito, durabilidade, grau de intensidade, origem, tipo em que se manifesta e abrangência, permitindo assim, uma interpretação multidimensional em estudos que se dizem respeito a esta temática. $\mathrm{O}$ dano de um determinado impacto estará sempre atribuído na sua tipologia, podendo ser de mais simples sem tantas consequências ruins até os mais complexos, sem reparo ou sem tentativa de minimização.

\section{Caracterização das áreas de estudo}

O município de Teresina possui uma área de 1.391,981 km²e limita-se com os municípios ao norte com União e José de Freitas, ao leste com Altos, ao sul com Nazária, Demerval Lobão, Altos, Monsenhor Gil, Curralinhos Lagoa do Piauí e Palmeirais e no Maranhão, com Timon e Caxias. O bairro Distrito Industrial possui uma área de $1,97 \mathrm{~km}^{2}$, limita-se ao norte com o bairro Saci, ao sul com o bairro Areias, a leste com os bairros Parque Piauí e Promorar e a oeste com o rio Parnaíba (TERESINA, 2018).

Em relação à habitação, conforme censo do IBGE em 2010 o bairro possuía 1.331 domicílios em 2010, quatro aglomerados subnormais, a citar: Afonso Gil I (496 domicílios, com 1731 pessoas); Carolina Silva (280 domicílios, com 1.027 pessoas); Nossa Senhora do Rosário (85 domicílios, com 306 pessoas) e Santa Maria (106 domicílios, com 379 pessoas). De acordo com a prefeitura, o bairro possui as vilas: Santa Rosa, Parque Saci e Areias; possui os parques: Industrial e Afonso Gil (TERESINA, 2018). Dos dados encontrados, o que chamou atenção é que $42 \%$ dos domicílios ocupados não possuíam coleta de lixo, uma porcentagem considerável, tendo em vista que representa quase a metade do número de domicílios.

De acordo com o mapa de zoneamento do uso do solo de Teresina, o bairro Distrito Industrial é composto por quatro áreas: Zona Industrial ZI (caracterizada por áreas de concentração de atividades industriais de baixo ou médio nível de desconforto ambiental); Zona de Proteção Ambiental ZP 6 e ZP 8 (são 
áreas de urbanização limitada em decorrência do interesse de preservação de espaços verdes e sítios históricos e/ou culturais) e Zona Residencial ZR1 (caracterizada por ocupação de baixa densidade, em lotes adequados para programas de interesse social) conforme mostra a Figura 4.

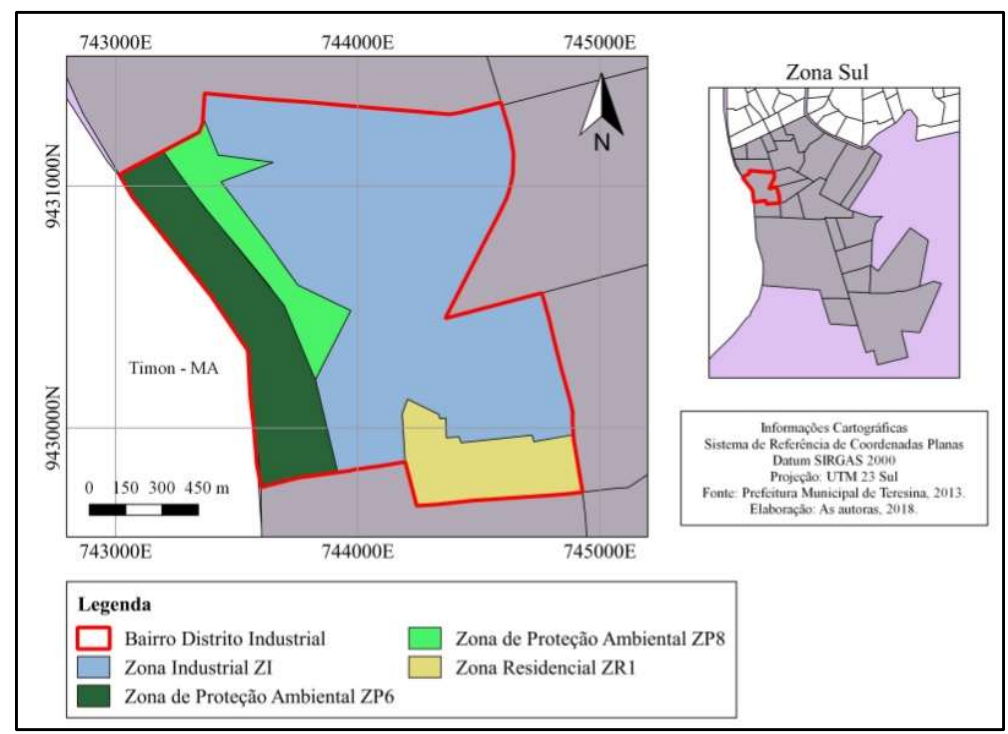

Figura 4: Zoneamento de uso do solo do bairro Distrito Industrial.

Vê-se que mais da metade da área do bairro é uma zona destinada para a atividade industrial, as margens do rio Parnaíba é uma zona de proteção ambiental e uma área posterior a zona de proteção das margens do rio, é outra zona de proteção ambiental e por última, ao sul do bairro, uma área de zona residencial.

Conforme Resolução Conama (BRASIL, 1986), em seu artigo 2o, aborda que, distritos industriais e zonas estritamente industriais - ZEI dependerão de elaboração de estudo de impacto ambiental e respectivo relatório de impacto ambiental - RIMA, a serem submetidos à aprovação do órgão estadual competente, e do IBAMA em caráter supletivo, o licenciamento de atividades modificadoras do meio ambiente.

Sobre o bairro Pedra Miúda este possui uma área de 7, $38 \mathrm{~km}^{2}$, limita-se ao norte com os bairros Esplanada, Portal da Alegria e zona rural, ao sul e ao leste com a zona rural, e ao oeste, com a zona rural, bairro Angélica e Angelim (TERESINA, 2018). O bairro Pedra Miúda foi criado por meio da Lei no 4.423, de 16 de julho de 2013 e corresponde à área acrescida à zona urbana pela Lei no 2.515, de 01 de abril de 1997. Esta área antigamente pertencia ao bairro Esplanada e ao Polo Empresarial Sul e que foi desmembrado pela Lei no 4.423. Em razão disso, não é possível caracterizar os dados domiciliares do bairro, pois o último censo do IBGE foi em 2010 (TERESINA, 2018).

O que se sabe atualmente, é que o bairro Pedra Miúda possui o conjunto residencial Eduarda Costa, localizado na área sul do bairro, o condomínio residencial Polo Sul localizado ao norte do bairro e uma área residencial não identificada. Conforme o mapa de zoneamento do uso do solo de Teresina, o bairro Pedra Miúda é composto por quatro áreas: Zona Industrial ZI (caracterizada por áreas de concentração de atividades industriais de baixo ou médio nível de desconforto ambiental); Zona Residencial ZR 1 (caracterizada por ocupação de baixa densidade, em lotes adequados para programas de interesse social), Zona Residencial ZR 2 (caracterizada por ocupação de baixa densidade, em lotes de médio porte) e Zona de 
Serviço ZS1 (são áreas onde se concentram atividades de serviços e comércio atacadista, relacionadas à necessidade de tráfego pesado) conforme mostra a Figura 5.

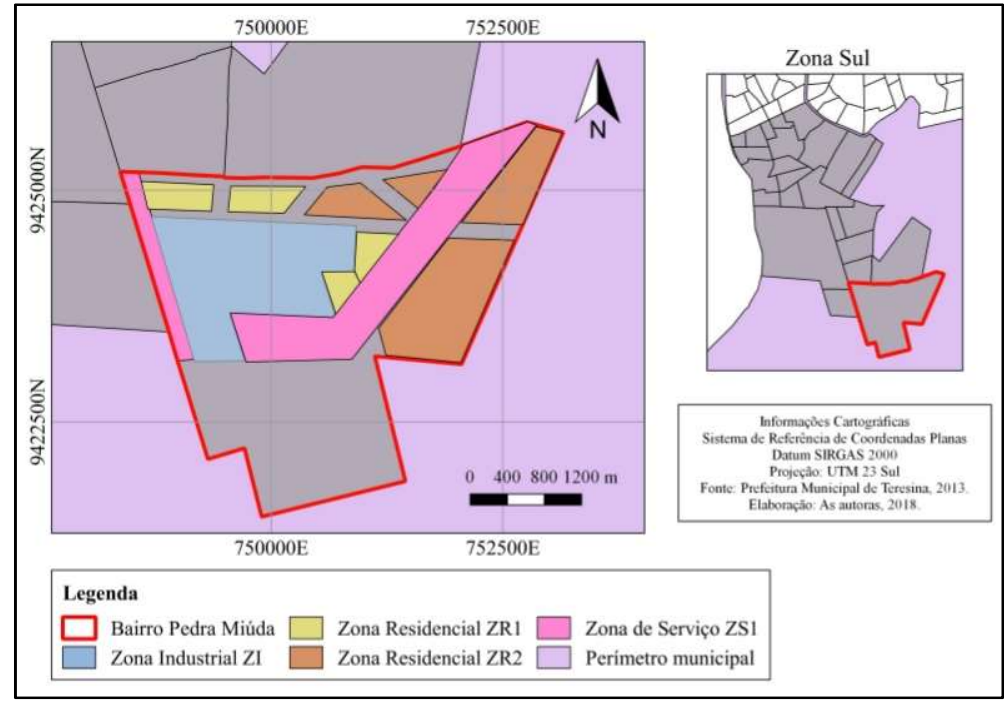

Figura 5: Zoneamento de uso do solo do bairro Pedra Miúda.

Analisando o mapa acima, nota-se que o bairro Pedra Miúda não foi feito o zoneamento de uso do solo correspondente a sua área total, faltando cerca de mais ou menos $35 \%$, que é aproximadamente as áreas do residencial Eduardo Costa e do residencial Orgulho do Piauí, inaugurado no início de 2014. Isso porque na época de confecção do mapa de zoneamento, em 2013, ainda não existia os referidos residenciais.

\section{RESULTADOS E DISCUSSÃO}

Foram encontradas 48 empresas de médio e grande porte, classificadas com porte 'Demais' pela Receita Federal em toda a zona Sul de Teresina/PI. Desse total, nove empresas encontradas durante análise de localização das empresas, não estão no cadastro industrial do FIEPI. As áreas de estudo são o bairro Distrito Industrial e a área do Polo Empresarial Sul, bairro Pedra Miúda a citar: a primeira possui 16 empresas de porte Demais, sendo que uma empresa não foi possível localizá-la com seus dados de endereço e três empresas foram localizadas, mas não estão registradas no cadastro industrial; a segunda possui 12 empresas de porte Demais, sendo que uma empresa não foi possível localizá-la e duas empresas foram localizadas, porém não estão no cadastro do FIEPI, conforme se observa na Figura 6.

Analisando o mapa, é notório que no bairro Distrito Industrial há maior presença de grandes empresas do segmento de alimentos e bebidas e no bairro Pedra Miúda, também a maior é do segmentos de alimentos e bebidas e de ferro e outros metais. Em conformidade com Lima et al. (2011), a chegada de diversas indústrias a um local determinado levam à criação de áreas industriais, de maneira que a chegada e também a saída de uma indústria de um determinado local modela a cidade e interfere na localização dos outros usos da terra, gerando também relações de emprego diversas.

A industrialização de uma área nem sempre traz a urbanização no sentido da qualidade (infraestrutura e melhoria da qualidade de vida da população), mas traz o conceito de urbanização em sentido quantitativo (no sentido do aumento da população urbana em detrimento da rural) (LIMA et al., 
2011). Sobre os impactos de vizinhança analisados em campo através da matriz, que por sua vez foram divididos em quatro segmentos (meio físico, aspectos urbanísticos, infraestrutura e qualidade de vida), constataram-se os seguintes impactos no segmento meio físico, conforme mostra o Quadro 2.

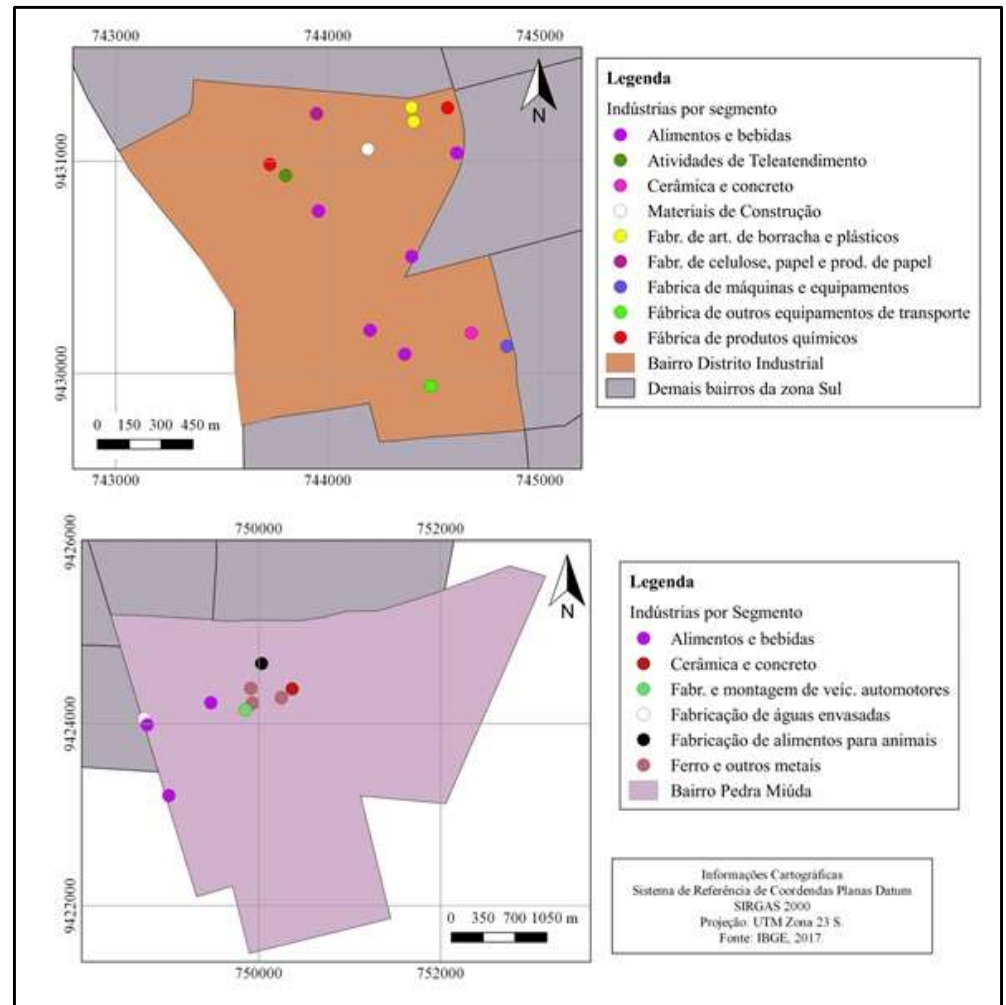

Figura 6: Espacialização das empresas por segmento no bairro Distrito Industrial e Pedra Miúda.

Quadro 2: Impactos identificados no meio físico.

\begin{tabular}{|l|l|l|l|l|}
\hline \multicolumn{1}{|c|}{ Meio Físico } & \multicolumn{4}{c|}{ Classificação } \\
\hline Impactos & \multicolumn{1}{|c|}{$\begin{array}{c}\text { Natureza } \\
\text { (Positivo/Negativo) }\end{array}$} & $\begin{array}{c}\text { Ordem } \\
\text { (Direta/Indireta) }\end{array}$ & $\begin{array}{c}\text { Magnitude } \\
\text { (Alto/Médio/Baixo) }\end{array}$ & $\begin{array}{c}\text { Duração } \\
\text { (Permanente/Temporário) }\end{array}$ \\
\hline Solo e rocha & Negativo & Direta & Alto & Permanente \\
\hline Relevo & Negativo & Direta & Alto & Permanente \\
\hline Paisagem Natural & Negativo & Direta & Alto & Permanente \\
\hline Vegetação & Negativo & Direta & Alto & Permanente \\
\hline Ocupação e uso do solo & Positivo & Direta & & Permanente \\
\hline
\end{tabular}

A cerca dos impactos no solo e rocha, relevo, paisagem natural e vegetação, são nítidos esses impactos ao se verificar em um intervalo de mais ou menos 10 anos. De acordo com Teobaldo Neto et al. (2007), em seu estudo sobre impactos ambientais no entorno de um distrito industrial em Uberaba, constataram que as atividades industriais representaram um forte impacto sobre os recursos ambientais: ar, água, vegetação e solo, sob as diversas formas de poluição. No decorrer desse tempo, ocorreu várias mudanças em ambos os bairros, pois estes expandiram suas áreas de uso e ocupação do solo, conforme se vê na Figura 7. Não foi possível verificar os impactos de água na superfície e água subterrânea.

Foi possível verificar através da imagem, várias áreas que antes eram ociosas. Isso é justificado no crescimento das atividades industriais e consequente expansão da área urbana através da lei de incentivos fiscais. Conforme explica Gonçalves (2010) a criação dos vazios urbanos podem ser consideradas causa e consequência da especulação imobiliária e da busca incessante da valorização de terras urbanas. Essas questões, interdependentes, nos fornecem um perfil da produção da cidade, que ao longo da definição dos 
espaços de usos coletivos ou privados, evidencia a força dos seus agentes produtores e reprodutores. A Figura 8 espacializa ocupação e uso do solo por áreas residenciais no bairro Distrito Industrial.

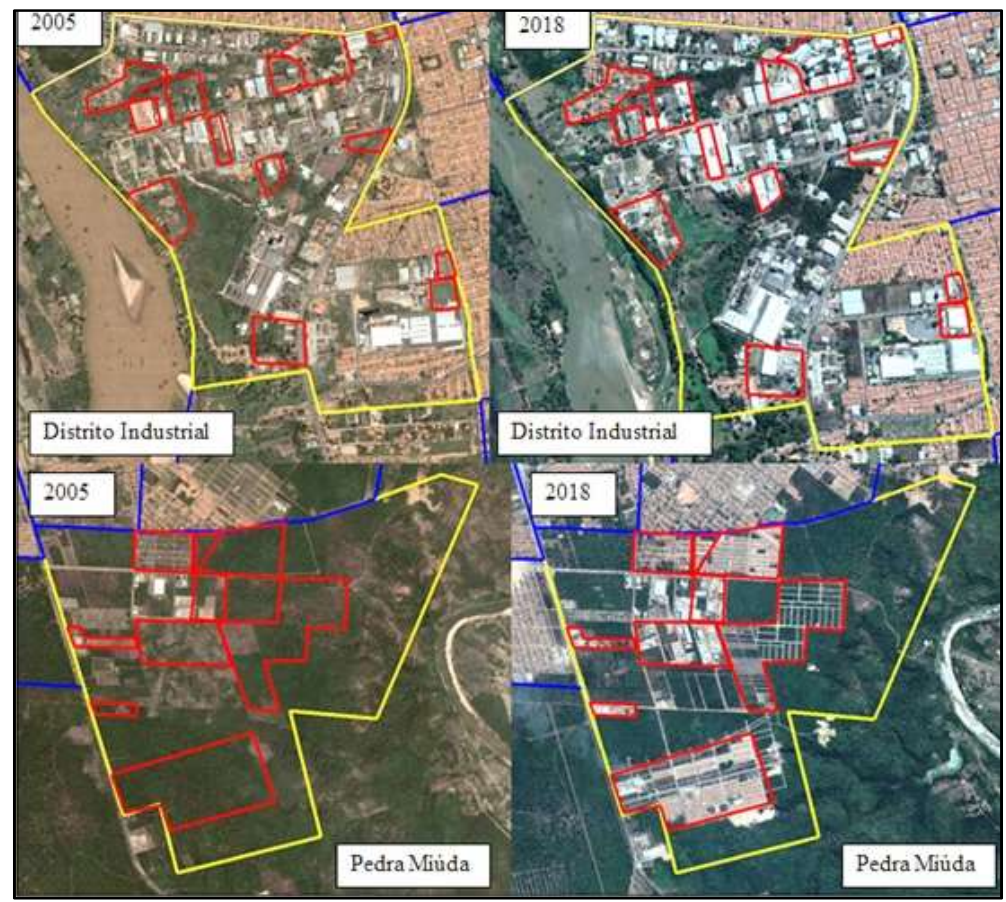

Figura 7: Evolução da ocupação de áreas entre 2005 e 2018.

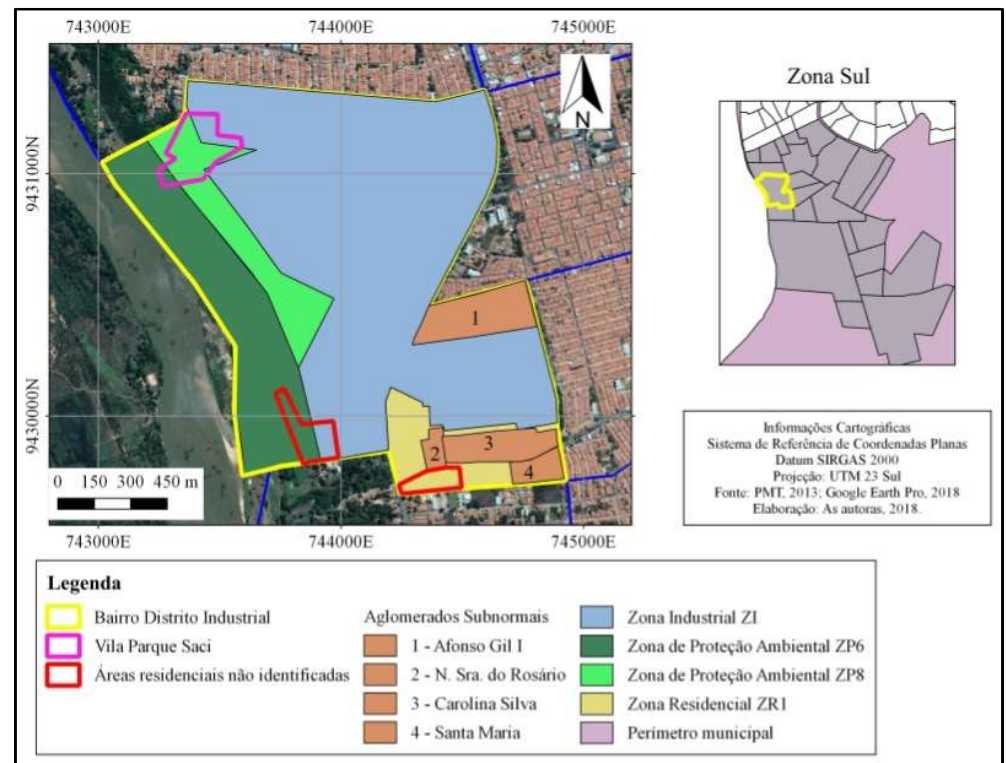

Figura 8: Mapa de ocupação e uso do solo no bairro Distrito Industrial.

Analisando a figura anterior, observa-se que existem duas áreas residenciais que estão ocupando as Zonas de Proteção Ambiental ZP6 E ZP8, o que deve ser visto com atenção pelo poder público municipal para tomar as devidas decisões cabíveis. Somente uma área com residências está dentro do espaço de zoneamento residencial. Ainda observa-se que o aglomerado subnormal Afonso Gil I, está dentro da área de zoneamento industrial.

Conforme a lei complementar $n^{\circ} 3.561$ (TERESINA, 2006), que dispõe sobre o parcelamento do solo urbano do município de Teresina, na Zona de Proteção Ambiental ZP6 não é permitido o parcelamento do solo e na Zona de Proteção Ambiental ZP8, é permitido, porém com restrição, apenas para o 
desenvolvimento de atividades agropecuárias, culturais, de recreação e de lazer e para a implantação de estações de tratamento de esgotos sanitários. A Figura 9 mostra através de mapa, a atual ocupação e uso do solo do bairro Pedra Miúda no que diz respeito a áreas residenciais.

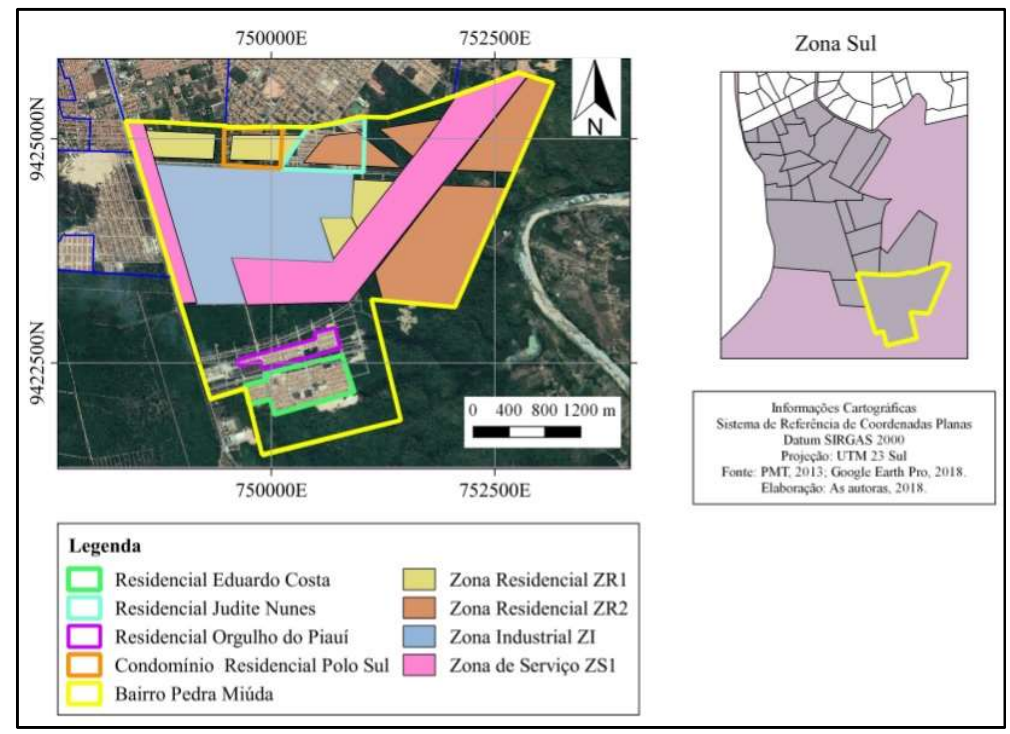

Figura 9: Mapa de ocupação e uso do solo no bairro Pedra Miúda.

Pode-se constatar que áreas dos residenciais Judite Nunes e Polo Sul estão nas zonas de residência ZR1 e ZR2, conforme zoneamento da prefeitura. O que não se sabe ao certo é se os residenciais Eduardo Costa e Orgulho do Piauí estão nas devidas zonas, pois ainda não estavam construídos em 2013 (ano em que o mapa de zoneamento foi feito). O bairro Pedra Miúda, diferente do bairro Distrito Industrial, não possui área de proteção ambiental. O Quadro 3 mostra os impactos analisado no que se refere aos aspectos urbanísticos como adensamento urbano e populacional, valorização imobiliária ventilação e iluminação, paisagem urbana e paisagem cultural.

Quadro 3: Impactos identificados no aspecto urbano.

\begin{tabular}{|c|c|c|c|c|}
\hline Aspetos Urbanísticos & \multicolumn{4}{|c|}{ Classificação } \\
\hline Impactos & $\begin{array}{c}\text { Natureza } \\
\text { (Positivo/Negativo) }\end{array}$ & $\begin{array}{c}\text { Ordem } \\
\text { (Direta/Indireta) }\end{array}$ & $\begin{array}{c}\text { Magnitude } \\
\text { (Alto/Médio/Baixo) }\end{array}$ & $\begin{array}{c}\text { Duração } \\
\text { (Permanente/Temporário) }\end{array}$ \\
\hline $\begin{array}{l}\text { Adensamento } \\
\text { Populacional }\end{array}$ & Negativo & Direta & Baixo & Permanente \\
\hline Adensamento Urbano & Positivo & Direta & Alto & Permanente \\
\hline Valorização Imobiliária & Positivo & Direta & Alto & Permanente \\
\hline $\begin{array}{ll}\begin{array}{l}\text { Ventilação } \\
\text { Iluminação }\end{array} & \mathrm{e} \\
\end{array}$ & Positivo & Direta & Alto & Permanente \\
\hline Paisagem Urbana & Positivo & Direta & Alto & Permanente \\
\hline
\end{tabular}

A cerca dos impactos de adensamento urbano e populacional, foi constatar nas figuras anteriormente mencionadas. Consequente, esses impactos (adensamento urbano e populacional) gera demanda por ventilação e iluminação. Interfere também na paisagem urbana que fica mais harmoniosa e valorizada. As áreas dos bairros em estudo não possuem patrimônio cultural. A Figura 10 mostra alguns registros da valorização imobiliária. 


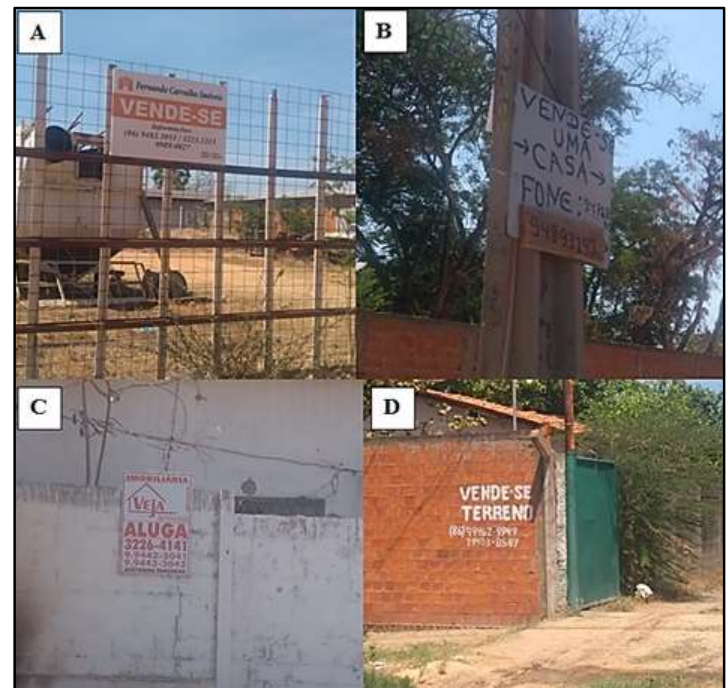

Figura 10: Placas de aluguel e venda de pontos, casa e terreno.

Com o adensamento populacional e urbano, modificando a paisagem urbana, é consequente o impacto da valorização imobiliária. Tais anúncios nesse local é justificado na circulação frequente dos transportes de produtos das indústrias e circulação de pessoas. O Quadro 4 mostra os impactos identificado na infraestrutura, como a geração de tráfego, demanda por transporte, rede de água, rede de esgoto, rede elétrica, estacionamento, alteração do sistema viário.

Quadro 4: Impactos identificados na infraestrutura.

\begin{tabular}{|c|c|c|c|c|}
\hline \multirow{2}{*}{$\begin{array}{c}\text { Infraestrutura } \\
\text { Impactos }\end{array}$} & \multicolumn{4}{|c|}{ Classificação } \\
\hline & $\begin{array}{c}\text { Natureza } \\
\text { (Positivo/Negativo) }\end{array}$ & $\begin{array}{c}\text { Ordem } \\
\text { (Direta/Indireta) }\end{array}$ & $\begin{array}{c}\text { Magnitude } \\
\text { (Alto/Médio/Baixo) }\end{array}$ & $\begin{array}{c}\text { Duração } \\
\text { (Permanente/Temporário) }\end{array}$ \\
\hline Geração de tráfego & Negativo & Direta & Baixo & Permanente \\
\hline $\begin{array}{l}\text { Demanda por } \\
\text { transporte }\end{array}$ & Positivo & Direta & Alto & Permanente \\
\hline Rede de água & Positivo & Direta & Alto & Permanente \\
\hline Rede de Esgoto & Positivo & Direta & Alto & Permanente \\
\hline $\begin{array}{l}\text { Rede de Drenagem } \\
\text { Pluvial }\end{array}$ & $\begin{array}{ll}----- \\
\end{array}$ & ------- & $\begin{array}{ll}---- \\
\end{array}$ & ------ \\
\hline Rede Elétrica & Positivo & Direta & Alto & Permanente \\
\hline Estacionamento & Positivo & Direta & Médio & Temporário \\
\hline $\begin{array}{l}\text { Alteração no Sistema } \\
\text { Viário }\end{array}$ & Positivo & Direto & Médio & Temporário \\
\hline
\end{tabular}

Em relação ao sistema viário e geração de tráfego na área das empresas, durante as observações foi possível constatar veículos com frequência média trafegando em alta velocidade, possivelmente por conta da ausência de pedestres no local, o que requereu uma atenção maior por parte das autoras durante o campo. As Figuras 10 e 11 mostram os impactos positivos e negativos respectivamente, encontrados na pesquisa de campo.

É importante destacar que nas áreas dos pontos de água servida e esgoto irregular encontrado, tinhase um forte odor, a ponto de ser necessário cobrir o nariz, uma vez que, estava causando incômodo. Por último, foram identificados e analisados os impactos na qualidade de vida da vizinhança, que foram os ruídos, resíduos sólidos e geração de emprego, conforme mostra o Quadro 5. 


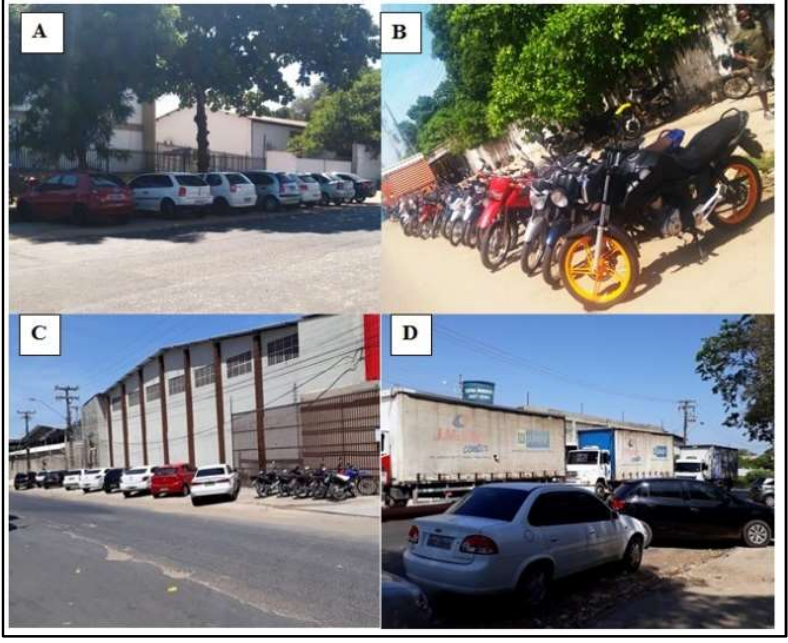

Figura 11: Estacionamentos.

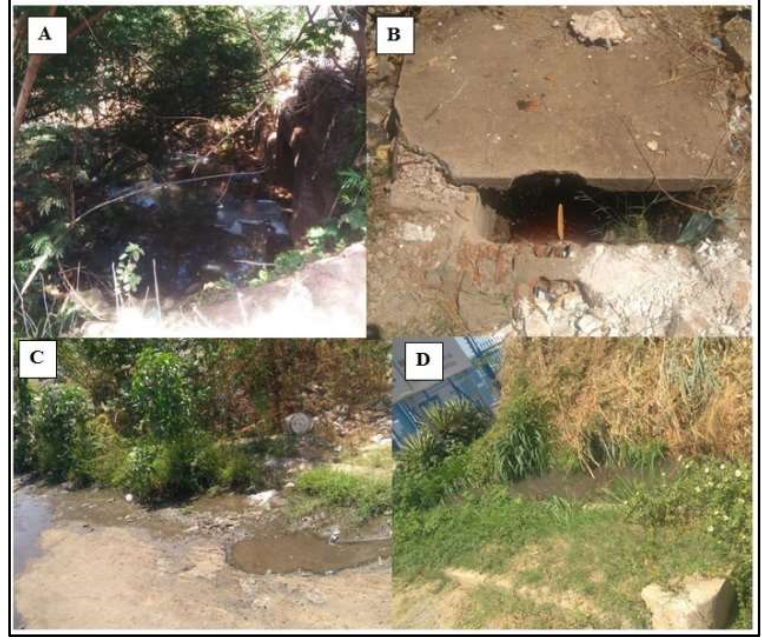

Figura 12: Pontos de água servida acumulada.

Quadro 5: Impactos identificados na qualidade de vida da vizinhança.

\begin{tabular}{|l|l|l|l|l|}
\hline Qualidade de Vida & Classificação \\
\hline Impactos & Natureza (Positivo/Negativo) & $\begin{array}{l}\text { Ordem } \\
\text { (Direta/Indireta) }\end{array}$ & $\begin{array}{l}\text { Magnitude } \\
\text { (Alto/Médio/Baixo) }\end{array}$ & $\begin{array}{l}\text { Duração } \\
\text { (Permanente/Temporário) }\end{array}$ \\
\hline Ruídos & Negativo & Direta & Baixo & Temporário \\
\hline Resíduos Sólidos & Negativo & Direta & Alto & Temporário \\
\hline Geração de emprego & Positivo & Direta & Alto & Temporário \\
\hline
\end{tabular}

O impacto de geração de emprego é eminente no processo de instalação de uma empresa. Conforme Linard et al. (2015), em seu estudo com quatro indústrias de cerâmica, constataram que geraram até outubro de 2010 o equivalente a 345 empregos diretos. Ainda de acordo com os autores, entre os impactos positivos mais relevantes foram apontados a geração de emprego e renda e o desenvolvimento local do município do Crato. Os ruídos encontrados no local foram devido ao tráfego de veículos dos mais diversos tipos, não foram encontrados ruídos incômodos vindos das indústrias. Em contrapartida, foram encontrados próximos as indústrias, resíduos sólidos e entulho, conforme se vê nas Figuras 13 e 14.

Os resíduos sólidos e entulhos podem trazer consequências sérias para a qualidade de vida da população e para o meio físico, a exemplo de mau cheiro, e em períodos de chuva, tais resíduos e entulhos podem obstruir esgotos e bueiros, colaborando para a formação de áreas alagadas. Oliveira (2006) em seu estudo monográfico encontrou cerca de sete empresas industriais que deixam seus resíduos sólidos jogados a céu aberto. Um detalhe que chamou atenção foram os diversos pontos de queimadas de lixo, como mostra a Figura 15.

De acordo com o artigo 47 da Lei n 12.305/2010 (Política Nacional de Resíduos Sólidos), a queima a céu aberto ou em recipiente, instalações e equipamentos não licenciados para essa finalidade, é uma forma proibida de destinação ou disposição final dos resíduos sólidos ou rejeitos (BRASIL, 2010). A queima de lixo traz consequências graves e em um raio de alcance considerável, tendo em vista que polui o ar e isso, impacta imediatamente na qualidade de vida da população podendo causar irritações nas vias respiratórias, dores de cabeça ou até mesmo doenças.

Vê-se que a prática de queima de lixo a céu aberto, é comum em empresas de segmento industrial, a citar Oliveira (2006), que em seu estudo, constatou que aproximadamente $30 \%$ das empresas queimam 
resíduos em seu próprio empreendimento ou nas proximidades. Com relação ao impacto de geração de emprego, foi bem notório pois em campo, foi possível constatar a circulação de pessoas com fardamentos das respectivas empresas deslocando-se para o local de trabalho, além de ter sido observado estacionamentos de diversos veículos próximo a entrada das empresas.

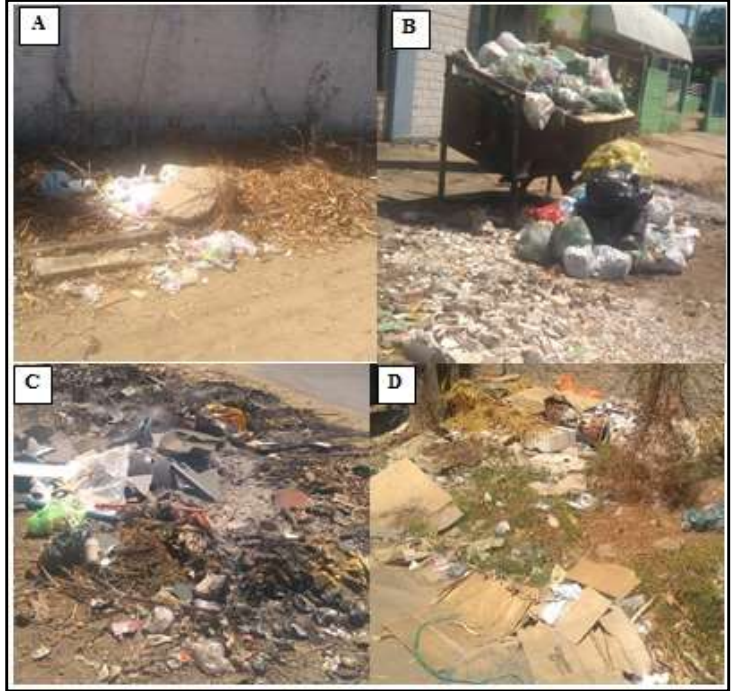

Figura 13: Resíduos sólidos.

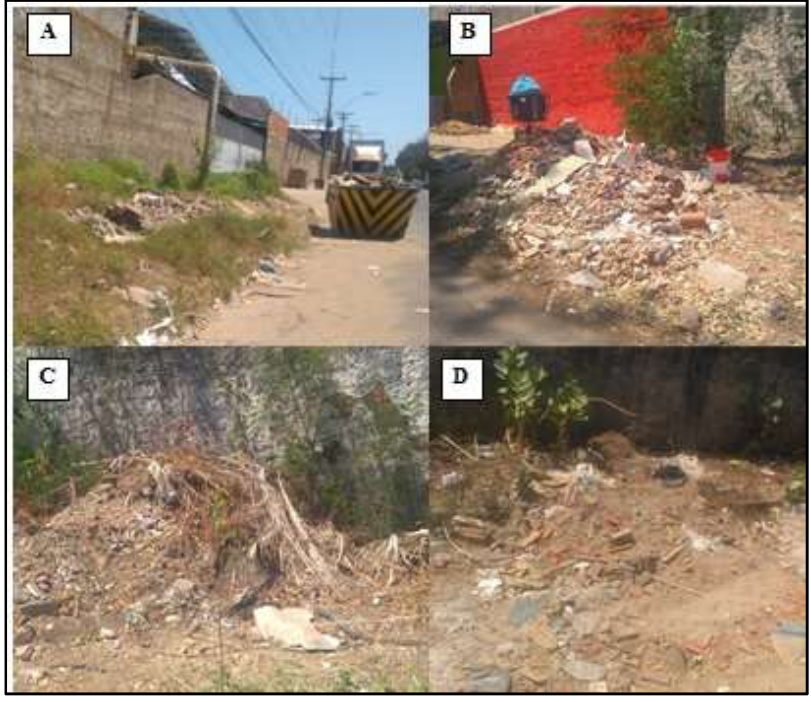

Figura 14: Entulhos.

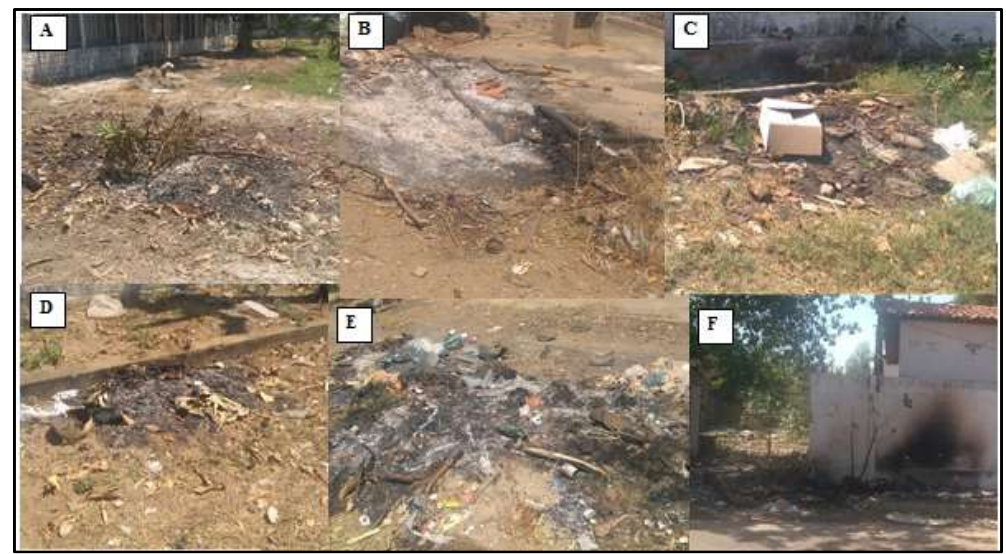

Figura 15 Pontos encontrados de queima de lixo.

\section{CONCLUSÕES}

Com base nos resultados apresentados, conclui-se que a aplicabilidade das ferramentas de geoprocessamento é de fundamental importância para a espacialização por meio de mapas temáticos de uso e ocupação do solo, visto que, essa visualização espacial possibilita um melhor entendimento da abrangência dos impactos na vizinhança e de áreas de ocupação irregular, servindo como uma ferramenta suporte para a tomada de decisões.

É necessária atenção por parte do Poder Municipal na adoção de medidas mitigadoras e compensatórias acerca dos impactos de vizinhança que interferem diretamente na qualidade de vida dos moradores, a exemplo dos canais de água servida, esgotos irregulares e deposição de resíduos sólidos e sua respectiva queima e das áreas de proteção ambiental que estão ocupadas por residências. 


\section{REFERÊNCIAS}

BRASIL. Lei n.10.257. 3 ed. Brasília: Senado Federal, Subsecretaria de Edições Técnicas, 2001.

BRASIL. Resolução CONAMA n.001: que dispõe sobre as definições, as responsabilidades, os critérios básicos e as diretrizes gerais para o uso e implementação da Avaliação de Impacto Ambiental. Ministério do Meio Ambiente. Brasília: CONAMA, 1986.

BRASIL. Lei n.12.305: Institui a Política Nacional de Resíduos Sólidos; altera a lei n.9.605, de 12 de fevereiro de 1998; e dá outras providencias. Brasília: DOU, 2010.

GONÇALVES, L. M.. Os vazios urbanos como elemento estruturador do planejamento urbano. In: CONGRESSO LUSO BRASILEIRO PARA O PLANEJAMENTO URBANO, REGIONAL, INTEGRADO, SUSTENTÁVEL, 4. Anais. São Carlos: EESC-USP, 2010.

IBGE. Instituto Brasileiro de Geografia e Estatística. Tabela de natureza jurídica. Rio de janeiro: IBGE, 2014.

KAPUSTA, S. C.; RODRIGUEZ, M. T. M. R.. Análise de impacto ambiental. Porto Alegre: Instituto Federal de Educação, Ciência e Tecnologia do Rio Grande do Sul, 2009.

LIMA, L. C.; SILVEIRA, R. M. C;; SILVA, B. L.; PEDROSA, L. P. D.; COSTA, A. A.. Espaço urbano e indústria: uma análise da dualidade locacional da SAMS e da COATS Corrente na região metropolitana de Natal. In: SEMANA DE HUMANIDADES,19. Anais. Natal: CCHLA, 2011.

LINARD, Z. U. S. A.; KHAN, A. S.; LIMA, P. V. P. S.. Percepções dos impactos ambientais da indústria de cerâmica no município de Crato estado do Ceará, Brasil. Economía, Sociedad y Territorio, México, v.15, n.48, p.397-423, 2015.

MOLINA JUNIOR, V. E.; LOLLO, J. A.; STANGANINI, F. N.. Estudo de Impacto de Vizinhança: metodologia para caracterização de impactos causados por supermercados em Ribeirão Preto/SP. In: SIMPÓSIO DE PÓS GRADUAÇÃO EM ENGENHARIA URBANA, 3. Anais. Maringá: UEM, 2013.

OLIVEIRA, C.. Impactos ambientais derivados de atividades industriais: o caso do CILO IV em Londrina. Monografia (Bacharelado em Geografia) - Universidade Estadual de Londrina, 2006.

TEOBALDO NETO, A.; SANTOS, D. G.; BRITO, J. L. S.. Os impactos ambientais urbanos no entorno do Distrito Industrial, em Uberaba (MG). Caminhos de Geografia, Uberlândia, v.8, n.24, p.1-14, 2007.

TERESINA. Lei n.3.565: Dispõe sobre o Estudo Prévio do Impacto de Vizinhança: EPIV e dá outras providências. Teresina: PMT, 2006.

TERESINA. Lei Complementar n.3.560: Define as diretrizes para o uso do solo urbano do Município e dá outras providências. Teresina: PMT, 2006.

TERESINA. Lei Complementar n.3.561: Dispõe sobre o parcelamento do solo urbano do Município de Teresina e dá outras providências. Teresina: PMT, 2006.

TERESINA. Mapa de Zoneamento Urbano. Teresina: PMT, 2013.

A CBPC - Companhia Brasileira de Produção Científica (CNPJ: 11.221.422/0001-03) detém os direitos materiais desta publicação. Os direitos referem-se à publicação do trabalho em qualquer parte do mundo, incluindo os direitos às renovações, expansões e disseminações da contribuição, bem como outros direitos subsidiários. Todos os trabalhos publicados eletronicamente poderão posteriormente ser publicados em coletâneas impressas sob coordenação da Sustenere Publishing, da Companhia Brasileira de Produção Científica e seus parceiros autorizados. Os (as) autores (as) preservam os direitos autorais, mas não têm permissão para a publicação da contribuição em outro meio, impresso ou digital, em português ou em tradução. 